\title{
A Model for Spatially Varying Crime Rates in English Districts: The Effects of Social Capital, Fragmentation, Deprivation and Urbanicity
}

\author{
Peter Douglas Congdon*
}

\author{
Queen Mary, University of London, Mile End Road, London E1 4NS, UK
}

\begin{abstract}
Geographic variations in crime are often linked to aspects of urban social structure that are latent constructs, not directly observed but instead proxied by a range of observed indicators. Examples are area deprivation and urbanicity, both established risk factors for crime. Little UK based evidence exists for impacts on crime of other potentially relevant influences such as social capital and social fragmentation, which are also latent constructs. Other cited influences on area crime differences include income inequality, but there may be further unobserved factors, which tend to be spatially correlated. The present paper seeks to establish, using appropriate multivariate and spatial regression techniques, the relative importance of social capital, fragmentation, deprivation, urbanicity and income inequality in an analysis of recent crime variations between 324 English Local Authority Districts. Variations in total, violent and property crime are considered.
\end{abstract}

Keywords: Deprivation index, area crime rates, social capital index, urbanicity, spatial regression.

\section{INTRODUCTION}

Geographic variations in aggregate crime rates are often linked to urban social structure. However, many aspects of urban social structure can be viewed as latent constructs, not directly observed but instead proxied by a range of observed indicators. Examples are area deprivation and urbanicity, both of which are well established risk factors for crime. Little UK-based evidence exists for impacts on geographic crime differences of other potentially relevant influences such as social capital and social fragmentation, which are also latent constructs. Some proposed influences on area crime differences, such as income inequality (e.g. Hooghe et al. 2011) may, by contrast, be directly measured. The present paper seeks to establish, using appropriate techniques, the relative importance of social capital, fragmentation, deprivation, urbanicity and income inequality in an analysis of crime variations between 324 English Local Authority Districts.

Findings from regression analysis regarding the impacts of deprivation, social capital, and other latent factors on spatial differences in crime, may depend on how these factors are measured. Explanatory regression models for geographic variations in crime or other outcomes (e.g. health) often use single indicators to represent broader structural constructs, such as residential instability as a proxy for fragmentation (Osgood 2000), unemployment rates as a proxy for area deprivation (Kohfeld and Sprague 1988), or a

*Address correspondence to this author at the Queen Mary, University of London, Mile End Road, London E1 4NS, UK; Tel: 0207882 2778; Fax: 020 7882 7479; E-mail: p.congdon@qmul.ac.uk binary urban-rural dichotomy as a proxy fo rurbanicity (Dahly and Adair 2007). Using a particular indicator to represent the overall urban construct may underestimate its association with the outcome of interest (Shishehbor et al. 2006). Another common strategy is to include several indicators of a construct as regression predictors - for example, median household income, owner-occupied homes, unemployment rate and poverty rate as multiple measures of area socioeconomic status in Zhang and Peterson (2007). However, this is likely to cause multicollinearity (Kiely and Sergievsky 1991; Martin 2002), leading to attenuation of expected effects, or reversal in expected directions of effects (Singh-Manoux et al. 2002).

In the present paper the focus is on the relationship between crime rates and aspects of area social structure that are not directly observed. Therefore a preliminary multivariate analysis derives latent composite variables by principal component analysis from a larger set of observed indicators. Area scores on these composite variables are then used directly in crime rates regression, avoiding multicollinearity or reliance on single variable proxies.

Findings from area crime rate regressions may depend not only on how predictors are measured, but also on regression technique. Spatial clustering in overall crime levels and in particular types of crime is widely documented (e.g. Martin 2002), and models seeking to explain area differences in crime should take account of spatiality (Ratcliffe 2010; Collins et al. 2006; Porter and Purser 2010). In particular, it is likely that unobserved influences on crime rates will be spatially structured. Additionally while many regression 
treatments take crime rates as a normal variable via linear regression, Osgood (2000) argues that Poisson regression is more appropriate for crime count data.

The analysis below derives social capital, fragmentation, deprivation, and urbanicity scores from a broader set of input indices. It then uses spatial regression methods (as part of a Poisson regression) to analyze the impact of these constructs (and income inequality) on crime variations in the financial year 2009/10 between 324 English Local Authority Districts. Data are notifiable offences recorded by the police, and variations in total crime, violent crime (including robbery), and in theft/burglary combined (denoted as property crime)are considered. The following sections discuss impacts of urban structure on crime, derivation of construct scores and their association with crime, and the crime rate regressions.

\section{URBAN SOCIAL STRUCTURE AND CRIME}

\section{Urbanicity and Urban Environment}

A number of aspects of urban social structure have been linked to crime rate variations. First and foremost is the impact of the urban environment per se (as captured by urbanicity scores). A widely observed urban gradient in crime has been attributed inter alia to agglomeration effects in larger cities that facilitate crime interactions (Bettencourt et al. 2010), and to lower chances of arrest or recognition (Glaeser and Sacerdote 1999).

More specific aspects of the urban environment have been proposed as sources of crime clustering, such as links between alcohol outlet density and violent crime (Livingston 2008), between crime and the built environment (Matthews et al. 2010), and between property crime and road network accessibility (Beavon et al. 1994). The UK Government Home Office (2011a) reports consistent urban-rural gradients for various crime types, with a $55 \%$ higher overall crime rate in urban than rural areas according to the 2009/10 British Crime Survey.

\section{Area Socioeconomic Status}

Impacts of area socioeconomic status (e.g. as captured by area deprivation scores) on crime are also illustrated by UK data: the Home Office (2011b) reports a $62 \%$ higher crime rate in the most deprived neighbourhoods as compared to the least deprived. These variations may reflect both compositional effects, due to differences in the residential concentration of groups with different crime propensities, and contextual effects, that is effects of place per se (e.g. Pauwels 2010).

Different theoretical perspectives seek to explain why individual level disadvantage may increase criminal propensity. For example, Merton's strain theory is that deviance is more likely if people lack legitimate means to attain culturally valued goals. At individual level, higher chances of marginal employment or unemployment are associated with higher crime propensity (Crutchfield and Pitchford 1997), and because of residential differentiation in the location of different socioeconomic groups, these individual level linkages translate into aggregate level associations between area unemployment and crime (e.g. Kohfeld and Sprague 1988). Similarly individual level poverty and low educational attainment are associated with higher criminality (Sabates 2008), and by virtue of residential differentiation these linkages translate into area level associations.

Contextual effects captured by area socioeconomic indicators may include aspects of the built environment that are associated with crime (Schweitzer et al. 1999), lower community and social cohesion in deprived neighbourhoods, and differences in rates of crime reporting (Goudriaan 2006).

\section{Relative Deprivation}

A counter view to the importance of absolute deprivation on crime is that relative deprivation and perceptions of societal inequality are a more significant influence on crime (Davis 1959; Sack 1984; Hooghe et al. 2011). Aggregate area level studies (e.g. Brush 2007; Fajnzylber et al. 2002) of crime and income inequality provide some support for this view. However, some studies suggest that the effect of poverty may outweigh the influence of income inequality (Pridemore 2011).

\section{Social Fragmentation}

Also potentially relevant to explaining variation in area crime rates is neighbourhood social fragmentation, meaning low community integration associated with high residential turnover, short stay private sector renting (as distinct from public sector social rented housing), many nonfamily households, and many adults outside married relationships. An index combining such variables was used by Congdon (1996) to analyze area suicide contrasts, and a similar 
composite measure denoted 'residential instability' is applied by Matheson et al. (2006) to explain area variations in psychiatric morbidity. Area social fragmentation focuses on residential turnover and household composition and is conceptually distinct from area socioeconomic status: for example, some deprived areas (e.g. areas with high social renting) are characterised by low residential turnover.

The relevance of ecological or individual variables representing residential stability and family structure has been recognised in studies of crime variation. For example, Boggess and Hipp (2010), Sampson et al. (1997) and Martin (2002) analyze relationships between residential instability, social disorganization, and crime, while Sampson et al. (2006), IMAPP (2005) and Porter and Purser (2010) describe mechanisms by which marriage tends to reduce crime at both individual and ecological levels.

\section{Social Capital}

The above aspects of urban structure have all been linked to the formation of social capital, meaning norms of reciprocity and trust that promote civic participation, activity in social organizations or voluntary activity (Putnam 1995; Jochum 2003), and that tend to cause more positive views of the local neighbourhood (Glasgow Centre for Population Health 2011; Harper and Kelly 2003). Regarding linkages between neighbourhood fragmentation and social capital, McGahan (1972) reports that demographic characteristics such as length of residence, marital status and whether living alone are associated with positive neighbourhood views and interactions, while Rupasingha et al. (2006) mentions that married people have higher trust and community engagement than single people. Rupasingha et al. (2006) also mention that social capital may be less in highly urbanized settings, arguing that "metropolitan areas (cities and towns) are believed by Putnam (1995) to be less congenial to social connectedness than small towns and rural areas".

Low area socio-economic status manifested in high area deprivation has also been linked to lower social capital. Social disorganization models for crime stress the importance of contextual neighbourhood influences on crime, and the role that concentrated area poverty has in reducing social control, with a consequent adverse impact on crime (Ackerman 1998; Martin 2002; Sampson et al. 1997). As Hoogh et al. (2011) state: "economic disadvantage and social exclusion ... erode networks of solidarity and trust...[and] reduce the collective efficacy of a local community".

As to the effect of social capital on crime, negative impacts have been reported by Akcomak and Weel (2008) in the Netherlands, and by Kennedy et al. (1998) and Sampson et al. (1997) on violent crime in the US. However, evidence for impacts of social capital on geographic crime differences is limited, and is often for highly aggregated regions (e.g. states in the US, or regions in Europe).

\section{Mediating Effects}

The potential effect of social capital on crime rates, combined with potential influences on social capital itself of area deprivation, urbanicity and fragmentation, suggests that explicitly including social capital in a spatial crime regression may mediate the effects on crime of these other urban dimensions (Baron and Kenny 1985). Such effects will be considered in the regression analysis below, and contribute to answering the question (in connection with violent crime variations) raised by Sampson et al. (1997: 918), namely "what is it ... about the concentration of poverty that accounts for its association with rates of violence? What are the social processes that might explain or mediate this relation."

Similar questions may be raised with regard to the effect of urbanicity on crime, namely whether this effect is partly an expression of social capital, though the literature suggests other intervening mechanisms such as varying road network access, location of crime generators and crime attractors (Brantingham and Brantingham 1993), chances of detection, and concentration of alcohol outlets (Gibbs and Haldenby 2006). Direct impacts of fragmentation and income inequality on crime (insofar as they exist) may be lessened if they operate largely through their impact on social capital; for example, Kennedy et al. (1998) find the effect of income inequality on firearm homicide is mediated in part by social capital.

Thus it may be hypothesized that impacts on crime of deprivation, fragmentation and urbanicity obtained in a regression model without social capital will be reduced when social capital is explicitly introduced as an additional influence. However, available measures of urban structure are unlikely to account for all crime variation, or for all spatial clustering in crime. One may anticipate the presence of a range of unmeasured but spatially structured influences on area crime rates, 
apparent in residual variation in crime that is spatially structured.

\section{DERIVING CONSTRUCT SCORES AND ASSOCIATED CRIME GRADIENTS}

Several studies have provided deprivation and rurality scores at various geographic scales in the UK (e.g. Carstairs and Morris 1991; Harrington and O'Donoghue 1998). Social fragmentation scores for areas have also been derived mainly in connection with ecological studies of suicide and psychiatric morbidity. However, there is relatively little UK based work on geographically disaggregated indices of social capital.

\section{Social Capital Index}

Here six indicators of neighbourhood perception and volunteering activity from the 2008 UK Place Survey (DCLG 2009a) are used to measure social capital. These are the percent of respondents agreeing "their local area is a place where people from different backgrounds get on well together", the percent feeling "they belong to their immediate neighbourhood", the percent "satisfied with their local area as a place to live", the percent "who have given unpaid help at least once per month over the last 12 months", the percent "who think that anti-social behaviour is a problem in their local area", and the percent who "think there is a problem with people not treating each other with respect and consideration in their local area". The first four indicators are taken to be positive measures of social capital, and the final two indicators to benegative measures. The fourth indicator is a measure of structural social capital (e.g. participation in community and voluntary activity), while the others represent aspects of cognitive social capital (trust, shared norms) (Engströmet al. 2008).

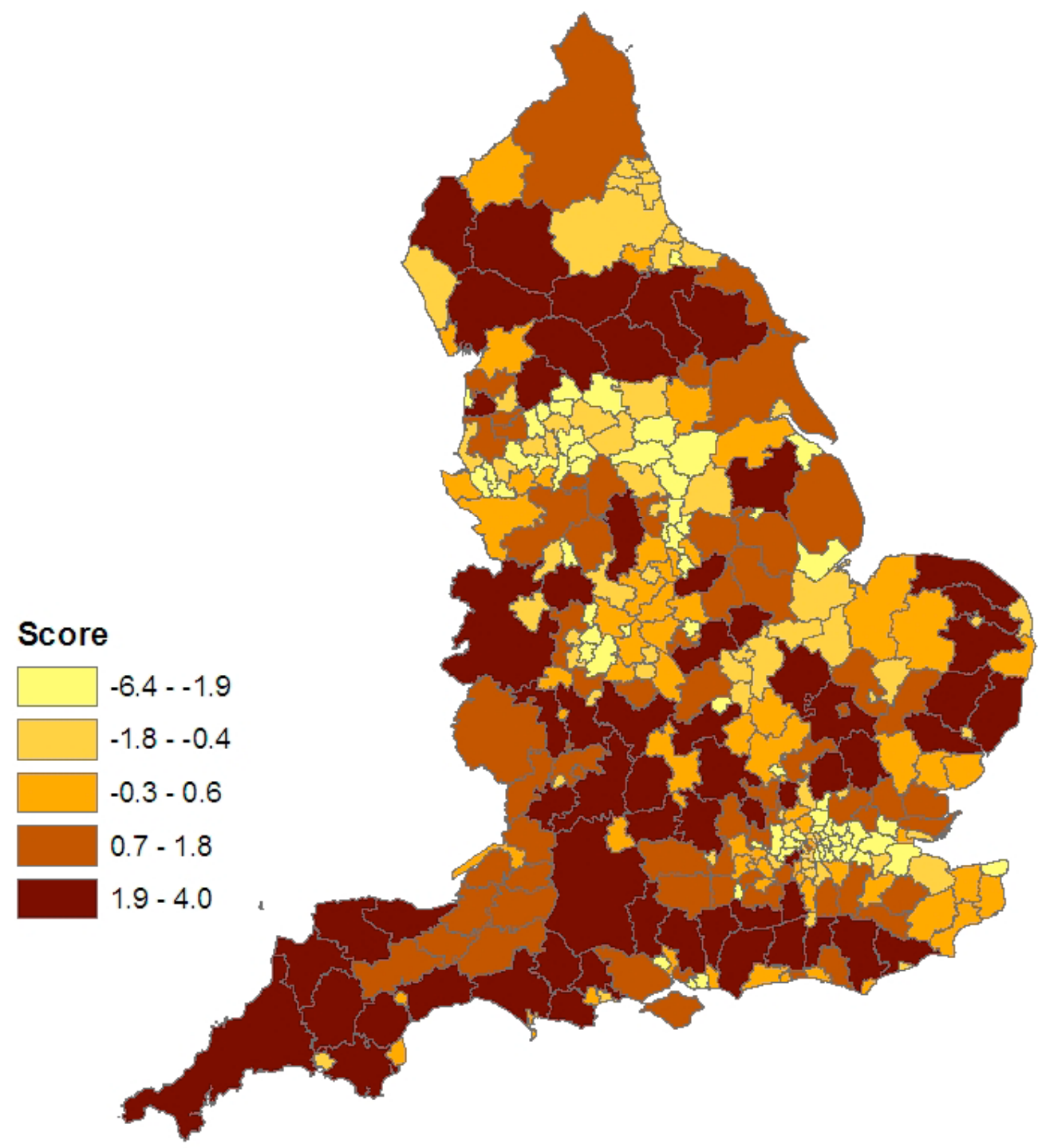

Figure 1: Social capital scores, English local authorities. 
Principal component analysis in STATA is used to obtain a composite score, with a leading eigenvalue of 4.54 , so that the first component accounts for $75.7 \%$ of the original variation. This supports the concept of a single latent variable underlying the six Place Survey indicators, and Figure 1 shows the distribution of the score, with higher scores away from core urban zones (concentrated on London, Birmingham, LiverpoolManchester, and the coastal north east). Figure 2 shows average social capital scores according to the region each District is located in. It can be seen that the South West region of England has higher average social capital than other regions; see similar findings for estimates of volunteering rates by Mohan et al. (2006). By contrast, London and North East England have below average social capital (cf. Schmuecker 2008). Such regional variations may partly reflect impacts of deprivation, fragmentation and urbanicity on social capital as mentioned above.

\section{Urbanicity Index}

To measure urbanicity (with converse rurality), two 2001 Census indices and three updated indicators are used. The latter are population density in 2009, the percent of land that is greenspace, and a measure of access to services. The percent of greenspace is obtained from the Generalised Land Use Database
Statistics (DCLG 2009b), and involves averaging over values for electoral wards within each Local Authority District. The access measure is obtained at lower super output area (LSOA) level as the sum of four inverse distances: to primary health care practitioners, to primary schools, to post offices, and to large retail stores. Averages over LSOAs within each Local Authority are then obtained. Census measures are the percent of housing consisting of flats, and the percent of the labour force in agriculture, forestry, or fishing (AFF). The indicators of flatted housing, population density and service access are positive measures of urbanicity, while the AFF and greenspace indicators are negative measures. The leading component accounts for $79.0 \%$ of the variation in these indicators, supporting an underlying latent dimension. The resulting urbanicity scores are plotted in Figure 3.

\section{Social Fragmentation Index}

To represent social fragmentation, the indicators are from the 2001 Census, namely migrant turnover in the precensal year, one person households, households in private sector renting, and percent of adults married. The leading component accounts for $78.8 \%$ of the variation in these indicators, supporting the assumption of a single underlying latent dimension.

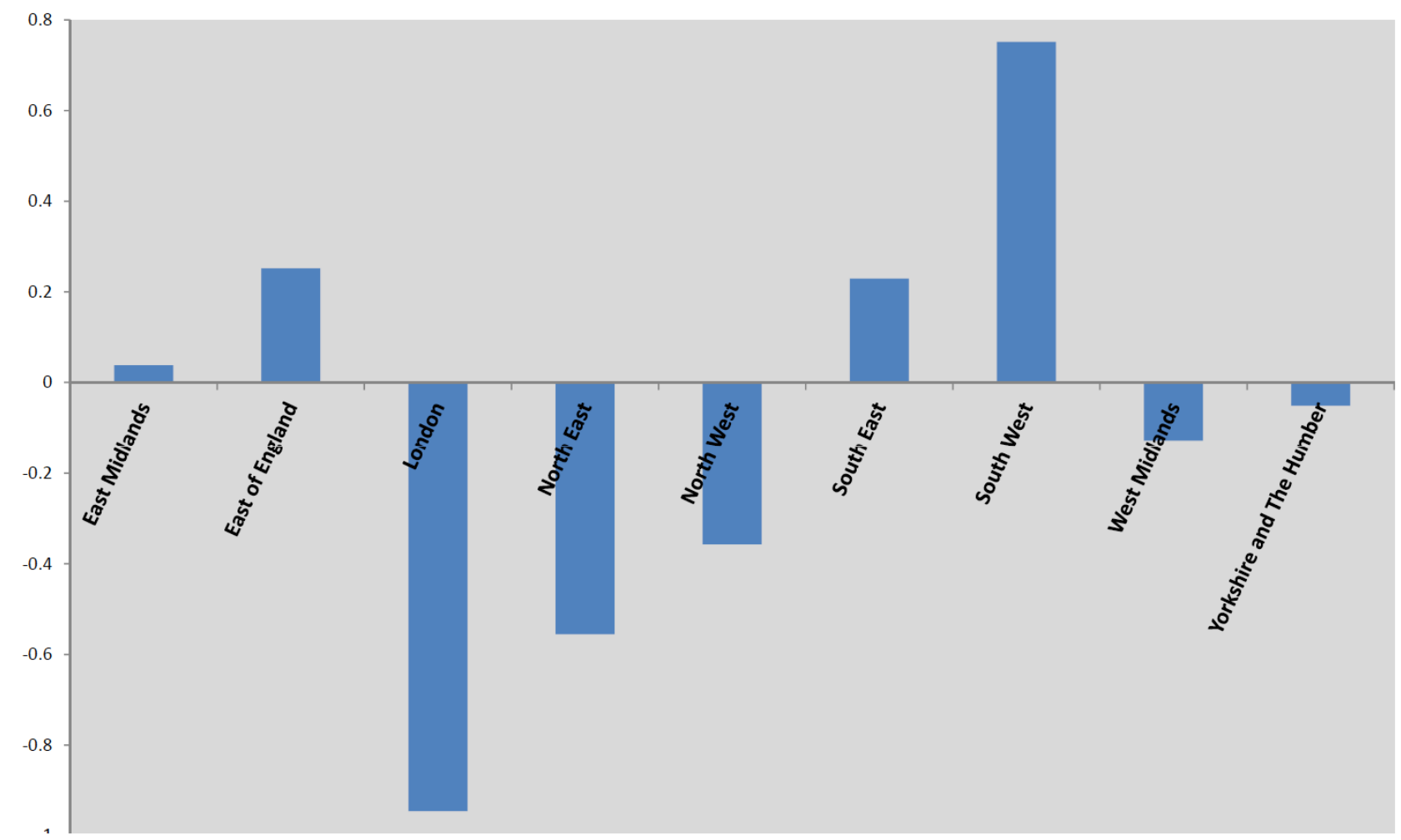

Figure 2: Average social capital scores by region. 


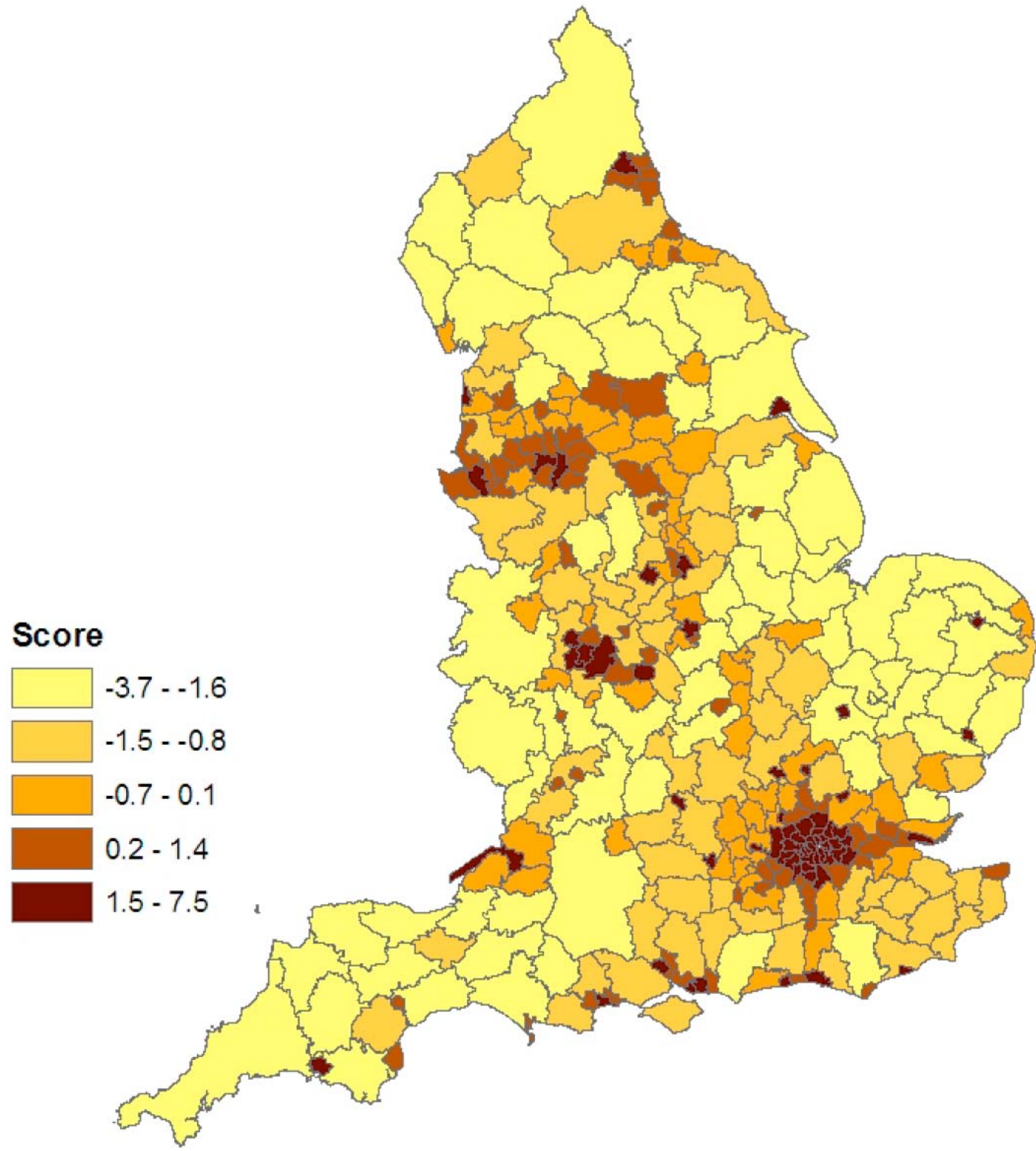

Figure 3: Urbanicity scores, english local authorities.

\section{Area Deprivation Index}

To represent area deprivation, the indicators used are percent of adults receiving income support (2008), the unemployment rate (2008), and two census variables: the percent of professional and managerial workers in the workforce, and the percent of adults over 20 with higher education qualifications. The leading component accounts for $70.5 \%$ of the variation in these indicators.

Table 1 shows correlations between the four constructs, with social capital negatively related to deprivation, urbanicity and (to a lesser extent) fragmentation. Fragmentation and deprivation are, however, only weakly positively correlated. Figure $\mathbf{4}$ groups Local Authorities into quintiles on their scores on fragmentation, deprivation and urbanicity, and shows declining social capital levels as scores on these other constructs increase.

\section{Crime Gradients by Construct Scores}

Table 2 shows gradients in total, violent and property crime rates according to construct quintiles: for example, the $20 \%$ of Local Authorities with highest social capital scores have a total crime rate of 38 per 1000 , as compared to a total crime rate of 86 per 1000 among the $20 \%$ of Local Authorities with the lowest social capital scores. The urbanicity effects are strongest (in terms of the crime ratio between $1^{\text {st }}$ and $5^{\text {th }}$ quintiles) for violent crime. However, gradients 
Table 1: Correlation between Construct Scores

\begin{tabular}{|c|c|c|c|}
\hline & Social Capital & Fragmentation & Urbanicity \\
\hline \hline Fragmentation & -0.30 & & \\
\hline Urbanicity & -0.63 & 0.69 & \\
\hline Deprivation & -0.70 & 0.07 & 0.21 \\
\hline
\end{tabular}
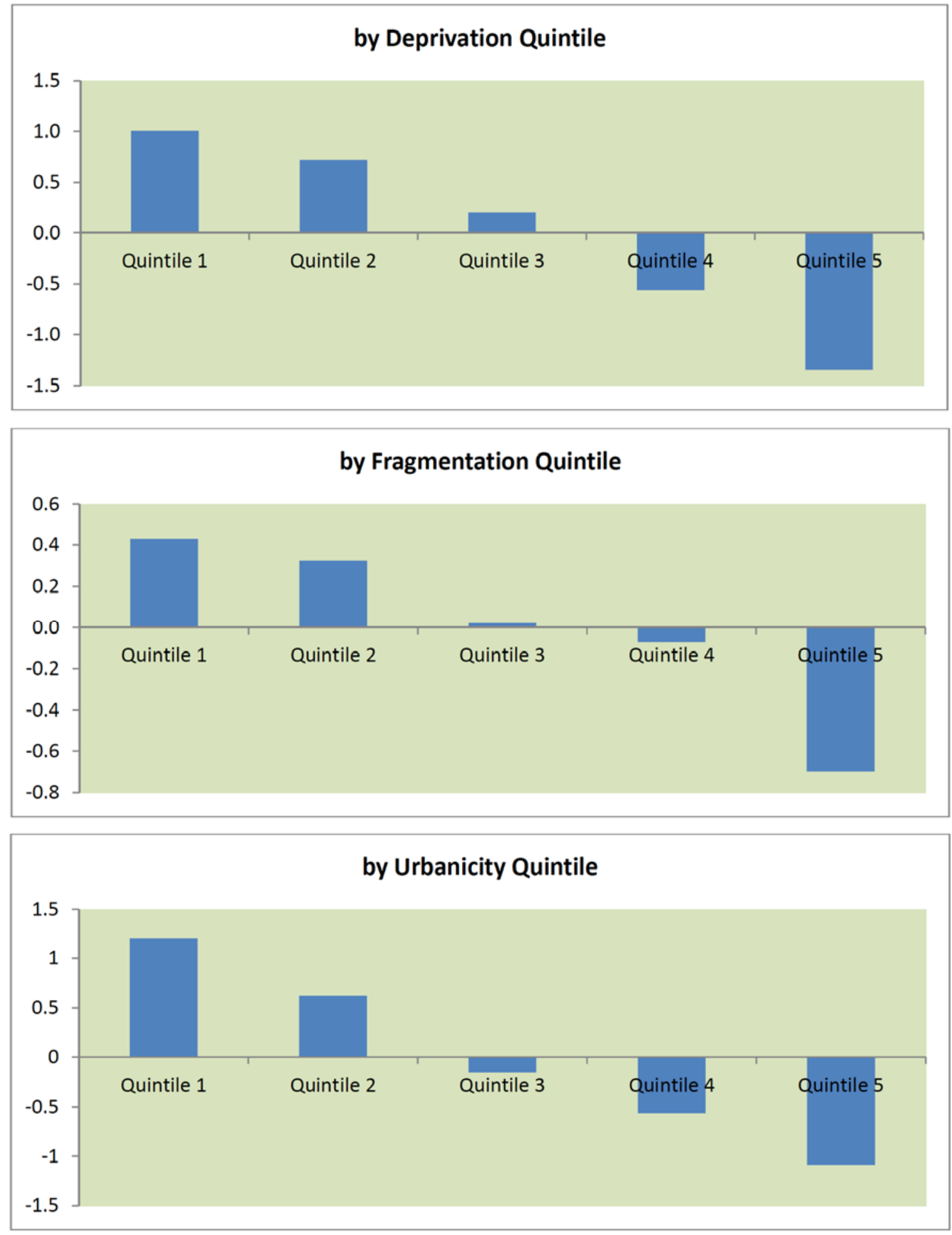

Figure 4: Average social capital (vertical axis) by construct score quintile. 
Table 2: Crime Rates (per 100 thousand) According to Urban Construct Category

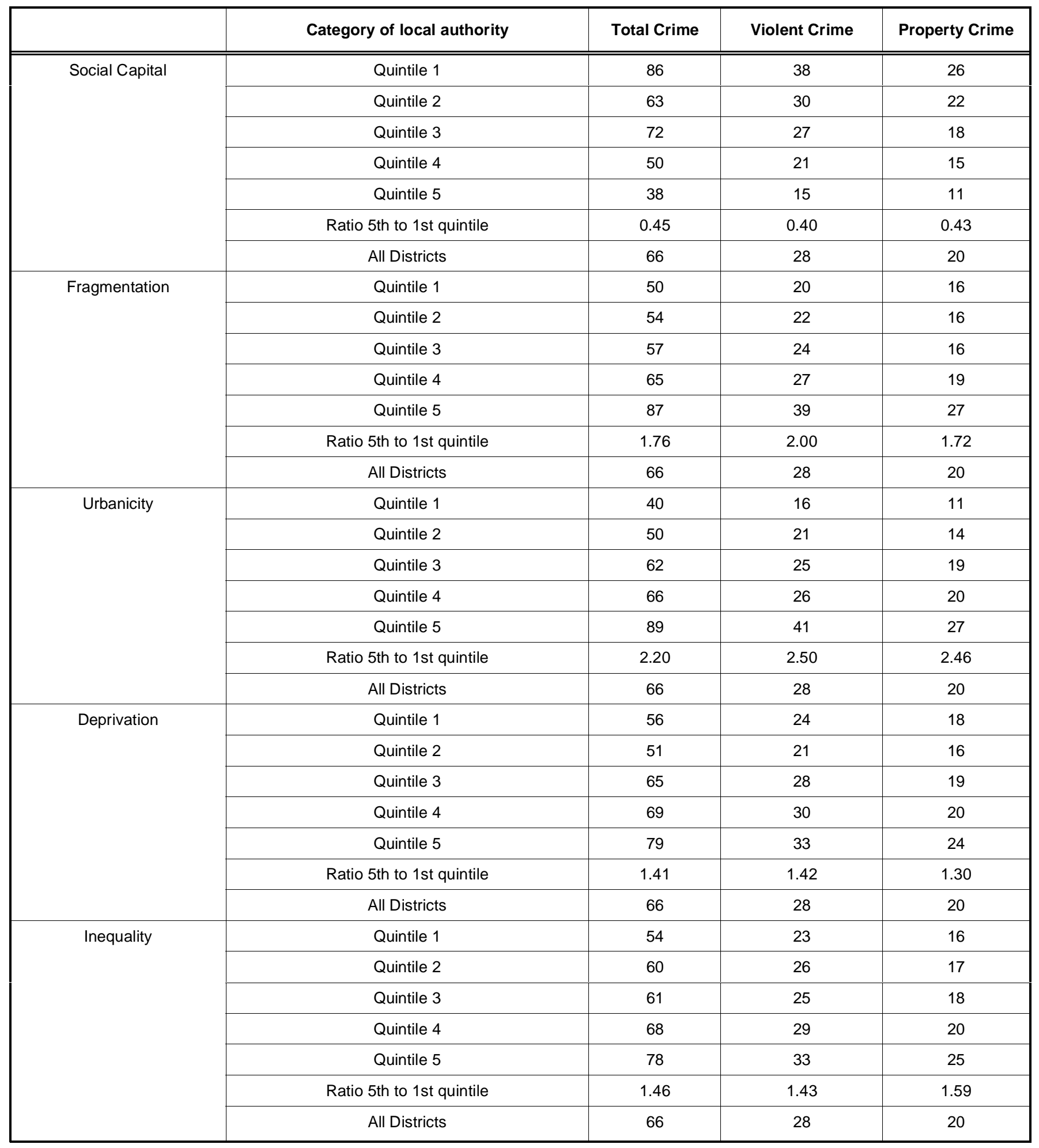

according to fragmentation and deprivation are also apparent. The fragmentation effect is also strongest for violent crime.

There is also a gradient with respect to a measure of income inequality, based on the coefficient of variation within each Local Authority of MSOA (middle level super output area) income estimates for 2007-08. Areas with lower intra-District inequality have lower crime levels, with the gradient most marked for property crime. 


\section{GEOGRAPHIC VARIATIONS IN CRIME RATES: SPATIAL REGRESSION}

To confirm these patterns a regression analysis is needed that controls for correlations between the predictors (the four constructs and income inequality), and that also allows for residual spatial dependence. The response variables are crime rates based on notifiable offences recorded by the police for 324 English Local Authorities. As earlier studies document, crime rates are spatially correlated and unmeasured spatially structured influences are likely to remain. Therefore regression residuals are here taken to be spatially correlated. Additionally a Poisson regression with log link is adopted (e.g. Osgood 2000). Even though a normal approximation may be used, especially for total crime rates, possibly after transformation (Martin, 2002: 135), the underlying event is still rare in relation to population at risk: the 2009/10 data show a rate of 0.065 for total offenses in relation to total population, with rates of 0.028 for violence, wounding and assault combined, and 0.020 for robbery, theft, and burglary combined.

Explanatory variables are provided by standardised scores on the four constructs, and by standardised income inequality. These are abbreviated in the regression equation below as SOCCAP, URBAN, SOCFRAG, DEPRIV, and INEQ. The residual term, denoted $U$, is a conditional autoregressive spatial random effect, and reductions in the marginal variance of $U$ can be used (as in Table 3 below) to indicate how much variation in relative crime rates between local authorities is explained as extra independent variables are added.

\section{Spatial Dependence in Residuals}

Conditional autoregressive models for spatial dependence have benefits in Bayesian estimation of models for area risk variations, for example in area disease models (Best et al. 2005:40). They express the effect $U_{i}$ for the $i^{\text {th }}$ area as a weighted average of effects $U_{k}$ in other areas, with weights $w_{i k}$ expressing distance decay; if the spatial interaction is represented by contiguity, the average is of effects in the "neighbourhood" $L_{i}$ of area $i$, namely the set of $d_{i}$ adjacent areas. As in Lee (2011), let $\lambda$ denote a parameter (between 0 and 1) encompassing alternative forms of unexplained variation in crime risk between areas. Then $U_{i}$ is normally distributed with mean $\lambda \bar{U}_{i} /\left(1-\lambda+\lambda \mathrm{d}_{\mathrm{i}}\right)$ and variance $\sigma^{2} \mathrm{u} /\left(1-\lambda+\lambda \mathrm{d}_{\mathrm{i}}\right)$, with $\bar{U}_{i}=\sum_{k \in L_{i}} U_{k} / d_{i}$ denoting the average of effects in neighbouring areas. This scheme has limits of pure spatial variation when $\lambda=1$, and no spatial interdependence when $\lambda=0$.

\section{Regression Form}

The regression adjusts for each area's weighted population aged 10 and over (WPOP) as an offset. Populations are weighted according to age structure, since the age group 18-24 has an elevated offending rate (over 3 times the all ages rate), while people over 50 have comparatively low offending rates (McVie 2005). The Poisson mean crime total in each area is the crime rate $\rho$ times the weighted population, WPOP. So if $Y_{i}$ denotes the observed crime total in the $i^{\text {th }}$ Local Authority, the Poisson model is

$Y_{i} \sim$ Poisson $\left(\rho_{i} W_{P O P}\right)$.

Table 3: Variation in Crime Risks Explained by Regression, and Moran I for Spatial Residuals

\begin{tabular}{|c|c|c|c|c|}
\hline & & All Crime & Violent Crime & Property crime \\
\hline \multirow{2}{*}{$\begin{array}{l}\text { Regression Model } 1 \text {, } \\
\text { Intercept only, Baseline } \\
\text { model }\end{array}$} & Baseline residual variance & 0.074 & 0.120 & 0.110 \\
\hline & Moran I (95\% interval in brackets) & $\begin{array}{c}0.258(0.253 \\
0.264)\end{array}$ & $\begin{array}{c}0.212(0.206 \\
0.218)\end{array}$ & $\begin{array}{c}0.495(0.487 \\
0.502)\end{array}$ \\
\hline \multirow{4}{*}{$\begin{array}{l}\text { Regression Model } 2 \\
\text { (excluding social } \\
\text { capital) }\end{array}$} & Remaining residual variance & 0.041 & 0.068 & 0.083 \\
\hline & $\%$ Baseline residual variance explained & 45 & 43 & 25 \\
\hline & Moran I (95\% interval in brackets) & $\begin{array}{c}0.185(0.179 \\
0.192)\end{array}$ & $\begin{array}{c}0.202(0.187 \\
0.218)\end{array}$ & $\begin{array}{c}0.460(0.442 \\
0.474)\end{array}$ \\
\hline & Pseudo-R-Squared (Percent) & 55 & 41 & 36 \\
\hline \multirow{4}{*}{$\begin{array}{l}\text { Regression Model } 3 \text { (all } \\
\text { predictors, including } \\
\text { social capital) }\end{array}$} & Remaining variance in log relative risks of crime & 0.036 & 0.063 & 0.067 \\
\hline & $\%$ Baseline residual variance explained & 51 & 47 & 39 \\
\hline & Moran I (95\% interval in brackets) & $\begin{array}{c}0.186(0.180 \\
0.192)\end{array}$ & $\begin{array}{c}0.230(0.204 \\
0.272)\end{array}$ & $\begin{array}{c}0.467(0.452 \\
0.484)\end{array}$ \\
\hline & Pseudo-R-Squared (Percent) & 59 & 43 & 45 \\
\hline
\end{tabular}


This model form is often used in analysing variations in relative risk of health (e.g. Best 1999), but has not been extensively applied in area crime analysis (though see Zhu et al. 2006). The crime rate for each Local Authority (including intercept $\alpha$ ) is modelled as

$\log \left(\rho_{i}\right)=\alpha+\beta_{1}$ SOCCAP $_{i} \quad+\beta_{2}$ SOCFRAG $_{i}+\beta_{3}$ DEPRIV $_{i}$ $+\beta_{4}$ URBAN $_{i}+\beta_{5}$ INEQ $_{i}+U_{i}$.

Since all predictors are standardised, the absolute size of the $\beta$ coefficients is a measure of the relative importance of a predictor in explaining crime rate variations.

Three crime rates are considered as responses: total crime; violence, wounding, robbery and assault combined; and theft and burglary combined. Estimation uses the WINBUGS package. A regression sequence is used to show (a) how much variation in relative crime risks is explained by the urban construct variables and inequality, and (b) how much of the effects of deprivation, fragmentation and urbanicity are mediated by social capital. So an initial model (model 1) has just an intercept only to provide an indication of total unexplained variation in relative crime risk; a second model (model 2) includes all predictors except SOCCAP; and a third model (model 3 ) includes all five predictors.

\section{Results of Regression}

Table 3 shows how variation in relative risks is explained by the predictors used. Two fit measures are used. One is the percent explained of the baseline residual variance (i.e. the variance of $U_{i}$ in a model with intercept only). The other is a pseudo- $R^{2}$ measure for Poisson regression (Cameron and Trivedi 1998). Table 3 shows that the full model including social capital explains $51 \%$ of baseline residual variation, as against $47 \%$ of violent crime variance, and $39 \%$ of property crime variance. This compares to percents explained in the model without social capital of $45 \%$ (all crime), $43 \%$ (violent crime) and $25 \%$ (property crime). Hence property crime seems to be relatively more influenced by social capital. A similar pattern holds for the pseudo$\mathrm{R}^{2}$ measures, which show greater improvement for property crime when social capital is added.

To assess the spatial correlation in the residual effects, the Moran I coefficient is monitored during the iterative estimation process (see Table 3). Spatial correlation is seen to be highest for property crime. It is apparent also that even when measured aspects of urban structure are allowed for, residual variation in crime risk remains significantly spatially structured, with 95\% credible intervals for Moran coefficients confined to positive values. This indicates spatially concentrated clusters of Local Authority areas where crime is below or above average, and these deviations have explanations beyond the four urban dimensions.

Results of the regression are also shown in Table 4 in terms of $\beta$-coefficients. The first three columns of Table 4 show the posterior mean, and 95\% credible intervals (analogous to classical confidence intervals) for the regression parameters. Also shown are the implied relative crime risk based on the $5^{\text {th }}$ and $95^{\text {th }}$ percentiles of each predictor. For example, the standardised social capital scores have $5^{\text {th }}$ and $95^{\text {th }}$ percentiles -1.63 and 1.54 , so that the relative crime risks in areas with low and high social capital levels (and average levels of other predictors) are $\exp (-$ $\left.1.63 \beta_{1}\right)$ and $\exp \left(1.54 \beta_{1}\right)$ respectively, where $\beta_{1}$ is the estimate (posterior mean) of the coefficient. So the predicted ratio in crime rates between Local Authorities with extremes of high and low social capital is $\exp \left(3.17 \beta_{1}\right)$. In model 3 for all crime, $\beta_{1}$ is -0.083 and $\exp \left(3.17 \beta_{1}\right)$ is 0.77 , so that Local Authorities with high social capital have $23 \%$ lower crime than Local Authorities with low social capital.

\section{Regression Excluding and Including Social Capital (Models 2 and 3 )}

If social capital is not included as a predictor of varying crime (model 2 , top half of Table 4), deprivation is the strongest influence on all types of crime, whether $\beta$-coefficients or risk ratios between 5 th and 95th percentiles are considered. The strongest effect of urbanicity is on violent crime. Effects of fragmentation in enhancing all crime types are secondary though significant, with most impact on violent crime.

Effects of income inequality in model 2 are insignificant. A regression of total crime on income inequality as a single predictor shows a significantly positive $\beta$-coefficient (more crime in more unequal areas), and $6.5 \%$ of variation explained. However, allowing for other influences shows that effects of income inequality seem to be entirely mediated by deprivation, urbanicity and fragmentation.

When social capital is included (model 3 , lower half of Table 4), it is second in terms of impact (as reflected in the absolute $\beta$-coefficient) to deprivation for total crime and violent crime, but has the strongest impact 
Table 4: Predictor Effects (on Logarithm of Relative Crime Risk)

\begin{tabular}{|c|c|c|c|c|c|}
\hline \multirow[b]{2}{*}{ Model } & \multirow[b]{2}{*}{$\begin{array}{c}\text { Crime Response Variable and Predictor } \\
\text { Effect }\end{array}$} & \multicolumn{3}{|c|}{$\begin{array}{l}\text { Regression Coefficient Estimate (with } \\
95 \% \text { credible interval) }\end{array}$} & \multirow{2}{*}{$\begin{array}{l}\text { Implied ratio of crime } \\
\text { risk between } 5 \text { th and } \\
\text { 95th percentiles of } \\
\text { predictor }\end{array}$} \\
\hline & & $\begin{array}{c}\text { Estimate } \\
\text { (posterior mean) }\end{array}$ & $2.5 \%$ & $97.5 \%$ & \\
\hline \multirow{11}{*}{$\begin{array}{l}\text { Regression Model } \\
\text { 2, excluding Social } \\
\text { Capital }\end{array}$} & All Crime & & & & \\
\hline & Effect of SOCFRAG $\left(\beta_{2}\right)$ & 0.049 & 0.024 & 0.072 & 1.17 \\
\hline & Effect of DEPRIV $\left(\beta_{4}\right)$ & 0.192 & 0.158 & 0.220 & 1.90 \\
\hline & Effect of INEQ $\left(\beta_{5}\right)$ & 0.004 & -0.024 & 0.028 & 1.01 \\
\hline & Violent Crime & & & & \\
\hline & Effect of SOCFRAG $\left(\beta_{2}\right)$ & 0.065 & 0.043 & 0.092 & 1.23 \\
\hline & Property crime & & & & \\
\hline & Effect of SOCFRAG $\left(\beta_{2}\right)$ & 0.039 & 0.007 & 0.071 & 1.13 \\
\hline & Effect of URBAN $\left(\beta_{3}\right)$ & 0.068 & 0.011 & 0.114 & 1.22 \\
\hline & Effect of DEPRIV $\left(\beta_{4}\right)$ & 0.122 & 0.091 & 0.161 & 1.50 \\
\hline & Effect of INEQ $\left(\beta_{5}\right)$ & -0.005 & -0.025 & 0.016 & 0.98 \\
\hline \multirow{13}{*}{$\begin{array}{l}\text { Regression Model } \\
\text { 3, including Social } \\
\text { Capital }\end{array}$} & All Crime & & & & \\
\hline & Effect of $\operatorname{SOCCAP}\left(\beta_{1}\right)$ & -0.083 & -0.136 & -0.039 & 0.77 \\
\hline & Effect of $\operatorname{SOCCAP}\left(\beta_{1}\right)$ & -0.087 & -0.150 & -0.019 & 0.76 \\
\hline & Effect of SOCFRAG $\left(\beta_{2}\right)$ & 0.081 & 0.040 & 0.123 & 1.29 \\
\hline & Effect of URBAN $\left(\beta_{3}\right)$ & 0.048 & 0.003 & 0.095 & 1.15 \\
\hline & Effect of DEPRIV $\left(\beta_{4}\right)$ & 0.173 & 0.101 & 0.244 & 1.78 \\
\hline & Effect of INEQ $\left(\beta_{5}\right)$ & 0.008 & -0.019 & 0.036 & 1.03 \\
\hline & Property crime & & & & \\
\hline & Effect of $\operatorname{SOCCAP}\left(\beta_{1}\right)$ & -0.122 & -0.174 & -0.068 & 0.68 \\
\hline & Effect of SOCFRAG $\left(\beta_{2}\right)$ & 0.036 & 0.001 & 0.071 & 1.12 \\
\hline & Effect of URBAN $\left(\beta_{3}\right)$ & 0.051 & 0.001 & 0.108 & 1.16 \\
\hline & Effect of DEPRIV $\left(\beta_{4}\right)$ & 0.009 & -0.044 & 0.062 & 1.03 \\
\hline & Effect of INEQ $\left(\beta_{5}\right)$ & -0.002 & -0.027 & 0.025 & 0.99 \\
\hline
\end{tabular}

on property crime. Impacts on crime of urbanicity and deprivation are considerably reduced in regression model 3 , in line with their effects being partially or completely mediated by social capital. In fact, under regression model 3 , deprivation no longer has a significant impact on property crime - so providing an 


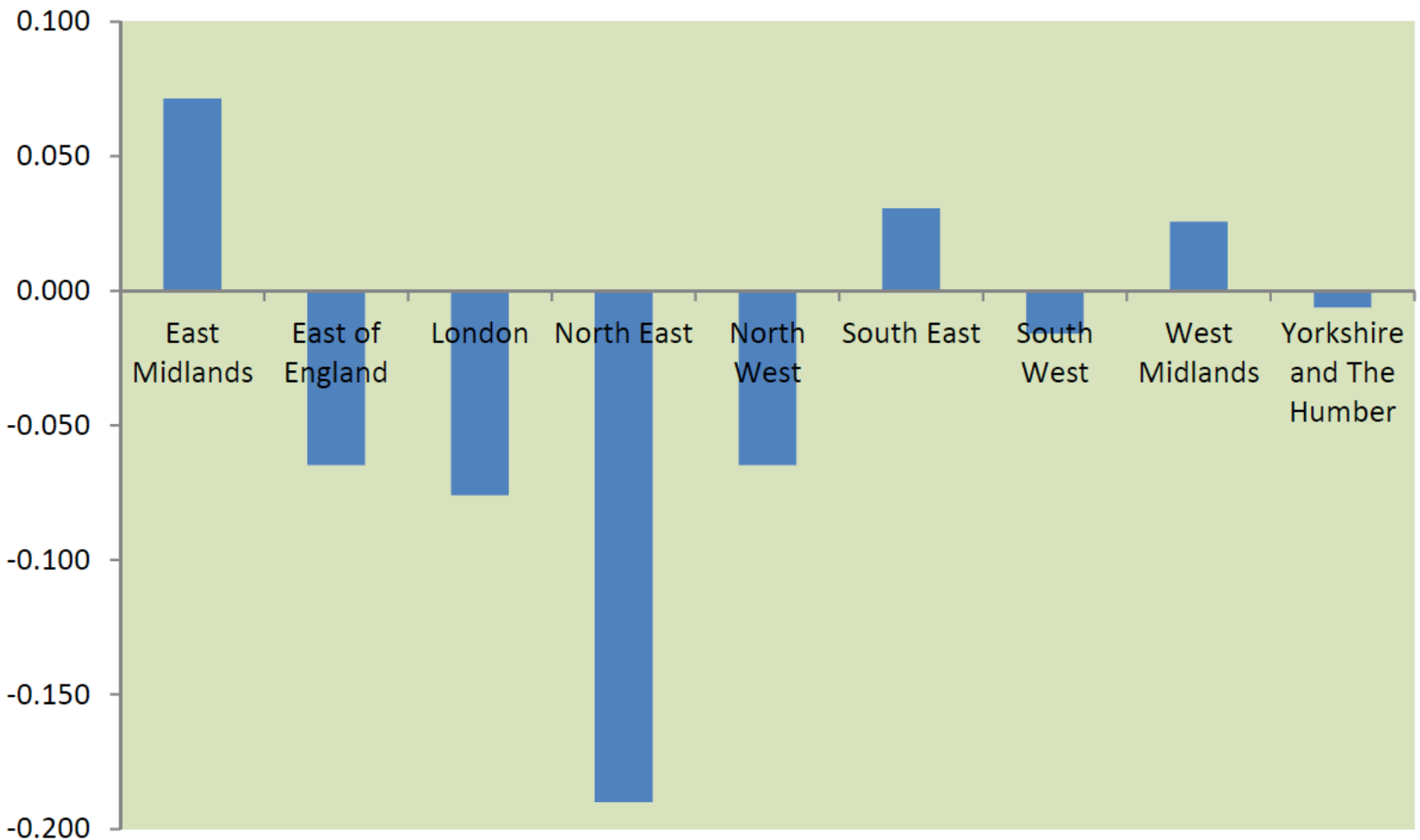

Figure 5: Average spatial residual by english standard region.

example of complete mediation (Baron and Kenny 1986). Similarly, the urbanicity effect on total crime becomes nonsignificant when social capital is allowed for. Effects of urbanicity on violent crime are also reduced when social capital is included, with the $\beta$ coefficient being reduced by two thirds (from 0.135 to 0.048). The effects of fragmentation are maintained in the full model, so that fragmentation appears to be a distinct ecological influence on crime, and less subject to mediation by social capital.

Although not pursued here, the results from model 3 suggest that further improved explanation of varying crime rates could be obtained by modelling spatial trend, or by including regional indicators as additional predictors. For example, regional averages on the $U$ effects in the total crime regression (Figure 5) show lower crime than expected (after allowing for regression predictors) in the North East, and higher crime than expected in the East Midlands.

\section{CONCLUSIONS}

Relatively little evidence is available on the spatial pattern of social capital in the UK, or regarding its ecological impact on area crime rates. Beugelsdijk and van Schaik (2005) present evidence on differences in social capital between Western European regions including UK regions, but are concerned with impacts on economic growth rather than crime. Twigg et al. (2006) and Mohan et al. (2004) develop synthetic small area estimates of particular aspects of social capital (such as volunteering), but are concerned with impacts on health.

The present analysis uses community perception and volunteering data from the English Place Survey to derive a social capital index for 324 English Local Authorities, and shows that higher values on this index are associated with lower crime. This relationship is maintained after controlling for other influences such as deprivation, urban-rural status, fragmentation and inequality. As argued above, a composite score obtained by multivariate reduction is preferable in regression applications to using a single proxy indicator to represent the overall construct (cf. Dahly and Adair 2007). Including multiple indicators of a construct directly in a regression is likely to cause multicollinearity (Martin 2002).

Social capital effects are a significant influence in reducing violent crime, echoing the findings of Sampson et al. (1997) that "the differential ability of neighborhoods to realize the common values of residents and maintain effective social controls is a major source of neighbourhood variation in violence". 
However, social capital also impacts on property crime; this adds to evidence provided by Martin (2002: 141), in connection with spatially varying burglary rates, that community networks and civic participation mediate the effect of poverty. Including social capital in the spatial regressions for English Districts attenuated both the crime-deprivation link, especially for property crime, and the urbanicity-crime link, for both property and violent crime. This suggests that social capital effects, as well as factors such as chances of detection (Glaeser and Sacerdote 1996), mediate the effect of urbanicity on crime.

Such findings have potential policy relevance. As Corrado et al. (2005) point out, community crime prevention programs may combine both police-based approaches, and the development of social capital via community based initiatives in neighbourhoods with high levels of concentrated disadvantage. Efforts to improve social capital in such neighbourhoods have potential benefits beyond crime reduction, for example, in improved education outcomes or health behaviours (Government of Canada 2005).

\section{REFERENCES}

Ackerman, William. 1998. Socioeconomic correlations of increasing crime rate in smaller communities. Professional Geographer 50(3): 372-387.

http://dx.doi.org/10.1111/0033-0124.00127

Akcomak, Semih and Weel, Bas. 2008. The impact of social capital on crime: evidence from the Netherlands. Discussion Paper No. 3603. Institute for the Study of Labor: Bonn.

Baron, Reuben andKenny,David. 1986. The moderator-mediator variable distinction in social psychological research: conceptual, strategic, and statistical considerations. Journal of Personality and Social Psychology 51(6): 1173-1182. http://dx.doi.org/10.1037/0022-3514.51.6.1173

Beavon, Daniel, Brantingham, Patricia, and Brantingham, Paul. 1994. 'The Influence of Street Networks On the Patterning of Property Offenses', in Clarke R (ed), Crime Prevention Studies, Vol II. Willow Tree Press, New York, pp 149-163.

Best, Nicky (1999) 'Bayesian Ecological Modelling', in Lawson A, Biggeri A, Boehning D, Lessafre E, Viel J, Bertollini R (eds): Disease Mapping and Risk Assesment for Public Health. Wiley, Chichester, pp 193-201.

Best, Nicky, Richardson, Sylvia, and Thomson, Andrew. 2005. A comparison of Bayesian spatial models for disease mapping, Stat Methods Med Res 14(1): 35-59. http://dx.doi.org/10.1191/0962280205sm388oa

Bettencourt, Luís, Lobo, José, Strumsky, Deborah, and West, Geoffrey. 2010. Urban scaling and its deviations: revealing the structure of wealth, innovation and crime across cities. PLoS One. Nov 10; 5(11): e13541. http://dx.doi.org/10.1371/ journal.pone. 0013541

Beugelsdijk, Sjoerd and Van Schaik, Ton. 2005. Differences in social capital between 54 Western European regions, Regional Studies 39(8): 1053-64. http://dx.doi.org/10.1080/00343400500328040
Boggess,Lyndsay andHipp, John. 2010. Violent crime, residential instability and mobility: does the relationship differ in minority neighborhoods?J. Quantitative Criminology 26(3): 351-370. http://dx.doi.org/10.1007/s10940-010-9093-7

Brantingham, Patricia and Brantingham, Paul. 1993. Nodes, paths and edges: considerations on thecomplexity of crime and physical environment. J. Env. Psych 13(1): 3-28. http://dx.doi.org/10.1016/S0272-4944(05)80212-9

Brush, Jesse. 2007. Does income inequality lead to more crime? A comparison of cross-sectional and time-series analyses of United States counties. Economics Letters 96(2): 264-268. http://dx.doi.org/10.1016/j.econlet.2007.01.012

Cameron, Colin and Trivedi,Pravin. 1998.Regression Analysis of Count Data. Cambridge University Press, Cambridge. http://dx.doi.org/10.1017/CBO9780511814365

Cameron, James. 2001.Spatial Analysis of Crime in Appalachia. US Dept of Justice, Washington.http://www.ncjrs.gov/App/ Publications/abstract.aspx? $\mathrm{ID}=189560$

Carstairs, Vera and Morris, Russell. 1991.Deprivation and Health in Scotland. Aberdeen University Press, Aberdeen.

Collins, Krista, Babyak, Colin and Molone, Joanne.2006. Treatment of Spatial Autocorrelation in Geocoded Crime Data. In Proceedings of theAmerican Statistical Association Section on Survey Research Methods, pp 2864-2871. http://www.amstat.org/sections/srms/proceedings/y2006

Congdon, Peter. 1996. The incidence of suicide and parasuicide: a small area study, Urban Studies 33(1): 137-158. http://dx.doi.org/10.1080/00420989650012194

Corrado, Raymond, Cohen, Irwinand Davies, Garth. 2005. Social Capital and Community CrimePrevention Programs. In:Social Capital in Action: Thematic Policy Studies. Policy Research Initiative: Government of Canada, pp 116-132.

Crutchfield, Robertand Pitchford, Susan. 1997. Work and crime: the effects of labor stratification. Social Forces 76(1): 93-118. http://dx.doi.org/10.1093/sf/76.1.93

Dahly, Darren and Adair, Linda. 2007. Quantifying the urban environment: a scale measure of urbanicity outperforms the urban-rural dichotomy. SocSci Med. 64(7): 1407-1419. http://dx.doi.org/10.1016/j.socscimed.2006.11.019

Davis, James. 1959. A formal interpretation of the theory of relative deprivation. Sociometry 22(4): 280-296. http://dx.doi.org/10.2307/2786046

Department for Communities and Local Government. 2009a.Place Survey: England - Headline Results 2008. DCLG, London.

Department for Communities and Local Government. 2009b. Generalised Land Use Database, Update 2006. DCLG, London.

Engström, Karin, Mattsson, Fredrik, Järleborg, Anders, and Hallqvist, Johan. 2008. Contextual social capital as a risk factor for poor self-rated health: a multilevel analysis. Soc Sci Med. 66(11): 2268-80.

http://dx.doi.org/10.1016/j.socscimed.2008.01.019

Fajnzlber, Pablo, Lederman, Daniel and Loayza, Norman. 2002. Inequality and violent crime, Journal of Law and Economics, 45(1), 1-40.

http://dx.doi.org/10.1086/338347

Glaeser, Edward and Sacerdote, Bruce. 1999. Why is there more crime in cities? Journal of political economy 107(S6): S225S258.

http://dx.doi.org/10.1086/250109

Gibbs, Blair andHaldenby, Andrew. 2006. Urban crime rankings. Reform, London.

Glasgow Centre for Population Health. 2011. The Glasgow Indicators Project.http://www.understandingglasgow.com/indicators/soci al_capital/view_of_the_local_area 
Goudriaan, Heike. 2006. Reporting crime: effects of social context on the decision of victims to notify the police. Universal Press, Veenendaal, The Netherlands.

Government of Canada. 2005. Social Capital as a Public Policy Tool: Project Report. http://policyresearch.gc.ca/doclib/SC_ Synthesis_E.pdf

Graif, Corina and Sampson, Robert. 2009. Spatial heterogeneity in the effects of immigration and diversity on neighborhood homicide rates. Homicide Studies 13(3): 242-260. http://dx.doi.org/10.1177/1088767909336728

Harper, Rosalyn and Kelly, Maryanne. 2003.Measuring Social Capital in the United Kingdom.Office for National Statistics, London. socialcapital

Harrington, Vicki and O'Donoghue, Dan. 1998.Rurality in England and Wales 1991: areplication and extension of the 1981 rurality index, Sociologia Ruralis 38(2): 178-203. 10.1111/1467-9523.00071

Home Office. 2011a. Crime in England and Wales 2009/10: Findings from the British Crime Survey and police recorded crime. Table 7.02 Trends in BCS household incidence rates in urban and rural areas, 2001/02 to 2009/10. http://www.homeoffice.gov.uk/publications

Home Office. 2011b. Crime in England and Wales 2009/10: Findings from the British Crime Survey and police recorded crime. Table 7.01 Trends in BCS household incidence rates by level of deprivation in England, 2001/02 to 2009/10. http://www.homeoffice.gov.uk/publications

Hooghe, Marc, Vanhoutte, Bram, Hardyns, Wim, and Bircan, Tuba. 2011. Unemployment, inequality, poverty and crime. British Journal of Criminology, 51(1): 1-20. http://dx.doi.org/10.1093/bjc/azq067

Institute for Marriage and Public Policy. 2005.Can married parents prevent crime? Recent research on family structure and delinquency 2000-2005. iMAPP Policy Brief. Institute for Marriage and Public Policy: Washington.

Jochum, Veronique.2003. Social capital: beyond the theory. National Council for Voluntary Organizations, London.

Kennedy, Bruce, Kawachi, Ichiro, Prothrow-Stith, Deborah, Lochner, Kimberly, and Gupta, Vanita.1998. Social capital, income inequality, and firearm violent crime. SocSci Med. 47(1): 717.

\section{http://dx.doi.org/10.1016/S0277-9536(98)00097-5}

Kiely, John and Sergievsky, Gertrude.1991. Some conceptual problems in multivariable analyses of perinatal mortality, Paediatric and Perinatal Epidemiology, 5(3): 243-257. http://dx.doi.org/10.1111/j.1365-3016.1991.tb00707.x

Kohfeld, Carol and Sprague, John.1988. Urban unemployment drives urban crime. Urban Affairs Review, 24(2): 215-241. http://dx.doi.org/10.1177/004208168802400203

Lee, Duncan. 2011. A comparison of conditional autoregressive models used in Bayesian disease mapping. Spatial and Spatio-temporal Epidemiology, 2(2): 79-89. http://dx.doi.org/10.1016/i.sste.2011.03.001

Leroux, Brian, Lei, Xingye, and Breslow, Norman.1999. Estimation of disease rates in small areas: a new mixed model for spatial dependence, in M. Halloran, D. Berry (eds), Statistical models in epidemiology, the environment and clinical trials, Springer-Verlag, New York, pp. 135-178

Livingston, Michael. 2008. Alcohol outlet density and assault: a spatial analysis, Addiction, 103(4): 619-28. http://dx.doi.org/10.1111//.1360-0443.2008.02136.x

McGahan, Peter 1972. The neighbor role and neighboring in a highly urban area. The Sociological Quarterly, 13(3): 397-408. http://dx.doi.org/10.1111/j.1533-8525.1972.tb00822.x

McVie, Susan. 2005. Patterns of deviance underlying the age-crime curve: the long term evidence. British Society of Criminology E-Journal, 7, 1-15
Martin, David. 2002. Spatial patterns in residential burglary: assessing the effect of neighborhood social capital. J Contemporary Criminal Justice 18(2): 132-146. http://dx.doi.org/10.1177/1043986202018002002

Matheson, Flora, Moineddin, Rahim, Dunn, James, Creatore, Maria, Gozdyra, Piotr and Glazier, Richard.2006. Urban neighborhoods, chronic stress, gender and depression. Soc Sci Med. 63(10): 2604-16.

http://dx.doi.org/10.1016/i.socscimed.2006.07.001

Matthews, Stephen, Yang, Tse-Chuan, Hayslett, Karen, and Ruback, Barry. 2010. Built environment and property crime in Seattle, 1998-2000: a Bayesian analysis. Environment and Planning A 42(6): 1403-1420.

http://dx.doi.org/10.1068/a42393

Mohan, John, Barnard, Steve, Jones,Kelvyn, and Twigg Liz.2004.Social capital, geography and health: developing and applying small-area indicators of social capital in the explanation of health inequalities. In: Morgan, A and Swann, C (eds), Social capital for health: issues of definition, measurement and links to health.Health Development Agency, London, pp 83-110

Osgood, Wayne. 2000. Poisson-based regression analysis of aggregate crime rates. J. Quantitative Criminology, 16(1): 2143.

http://dx.doi.org/10.1023/A:1007521427059

Pauwels, Lieven. 2010. Disentangling neighborhood and school contextual variation in serious offending: assessing the effect of ecological disadvantage. In: Pauwels L, Hardyns W, Van de, Velde M (eds) Social Disorganization, Offending, Fear and Victimization. Boom Juridische Uitgevers, The Hague, pp. 121-144.

Porter, Jeremy and Purser, Christopher. 2010. Social disorganization, marriage, and reported crime: a spatial econometrics examination of family formation and criminal offending. J. Criminal Justice 38(5): 942-950. http://dx.doi.org/10.1016/j.jcrimjus.2010.06.011

Pridemore, William. 2011. Poverty matters: a reassessment of the inequality-homicide relationship in cross-national studies. $\mathrm{Br}$ J Criminol, 51(5): 739-772.

http://dx.doi.org/10.1093/bjc/azr019

Putnam, Robert. 1995. Tuning in, tuning out: the strange disappearance of social capital in America. Political Science and Politics 28(4): 664-683.

http://dx.doi.org/10.2307/420517

Ratcliffe, Jerry. 2010. Crime mapping: Spatial and temporal challenges, in Piquero, A. and Wiesburd, D. (Eds) Quantitative Criminology, Springer, New York, pp. 5-24. http://dx.doi.org/10.1007/978-0-387-77650-7 2

Rupasingha, Anil, Goetz, Stephan and Freshwater, David. 2006. The production of social capital in U.S. Counties. Journal of Socio-Economics, 35(1): 83-101. http://dx.doi.org/10.1016/j.socec.2005.11.001

Sabates, Ricardo. 2008.Educational Attainment and Juvenile Crime Area-Level Evidence Using Three Cohorts of Young People. British Journal of Criminology 48(3): 395-409. http://dx.doi.org/10.1093/bjc/azn003

Stack, Steven. 1984. Income inequality and property crime. Criminology, 22(2): 229-256.

http://dx.doi.org/10.1111/j.1745-9125.1984.tb00299.x

Sampson, Robert, Raudenbush, Stephen, and Earls, Felton.1997.Neighborhoods and violent crime: a multilevel study of collective efficacy. Science 277(5328): 918-24. http://dx.doi.org/10.1126/science.277.5328.918

Sampson Robert, Laub John, and Wimer, Christopher.2006. Does marriage reduce crime? a counterfactual approach to withinindividual causal effects. Criminology, 44(3): 465-508. http://dx.doi.org/10.1111/j.1745-9125.2006.00055.x 
Schmuecker, Katie. 2008.Social capital in the North East: how do we measure up? Northern Rock Foundation, Newcastle upon Tyne.

Shishehbor, Mehdi, Litaker, David, and Alter, David.2006. Socioeconomic status and mortality. Ann Intern Med, 144: 781782.

http://dx.doi.org/10.7326/0003-4819-144-10-200605160$\underline{00017}$

Schweitzer, John, Kim, June, and Mackin, Juliette.1999. The impact of the built environment on crime and fear of crime in urban neighborhoods. Journal of Urban Technology 6(3): 59-73. http://dx.doi.org/10.1080/10630739983588

Singh-Manoux, Archana, Clarke, Paul, and Marmot, Michael.2002. Multiple measures of socio-economic position and psychosocial health: proximal and distal measures. Int $\mathrm{J}$ Epidemiol, 31(6): 1192-1199.

http://dx.doi.org/10.1093/ije/31.6.1192
Twigg, Liz, Barnard, Steve, Mohan, John, and Jones, Kelvyn. 2006. Developing and evaluating small-area indicators of the neighbourhood social environment, Environment and Planning A 38(11): 2173-2192. http://dx.doi.org/10.1068/a36213

Zhang Hiafeng, and Peterson, Michael.2007. A spatial analysis of neighbourhood crime in Omaha, Nebraska using alternative measures of crime rates, Internet Journal of Criminology, 31, http://www.internetjournalofcriminology.com/

Zhu, Li, Gorman, Dennis, and Horel, Scott. 2006. Hierarchical Bayesian spatial models for alcohol availability, drug "hot spots" and violent crime. Int J Health Geogr. 5(1): 54. http://dx.doi.org/10.1186/1476-072X-5-54

DOI: http://dx.doi.org/10.6000/1929-4409.2013.02.14

(C) 2013 Peter Douglas Congdon; Licensee Lifescience Global.

This is an open access article licensed under the terms of the Creative Commons Attribution Non-Commercial License (http://creativecommons.org/licenses/by-nc/3.0/) which permits unrestricted, non-commercial use, distribution and reproduction in any medium, provided the work is properly cited. 